\title{
Computer Modeling of a Novel Mechanical Arrangement of a Free-Piston Stirling Engine
}

\author{
S. Ghozzi and R. Boukhanouf
}

\begin{abstract}
The principle of a new design of Free Piston Stirling Engine (FPSE) prototype for small-scale power generator, such as solar dish Stirling engine, has been described in this paper. The design uses a special bellows with high reliability and long life mechanical springs displacer and power piston. A mathematical model has been developed to analyze the thermal and dynamic performance of the engine as well as to evaluate the output power and thermal efficiency of the cycle. Two methods of Stirling cycle analysis, which are Ideal Adiabatic and Simple Analysis, were carried out in order to calculate the performance and efficiency of the conserved FPSE design. A computer program is in progress so that the thermal cycle of Stirling simulated. The results extracted from the simulation proved a valuable thermal efficiency and overall satisfactory performance for the new FPSE design.
\end{abstract}

Index Terms - Stirling engine, free piston, power generation, low temperature, small-scale system.

\section{INTRODUCTION}

Stirling engines are external combustion machines that can operate on any kind of thermal energy including waste heat, solar and biofuel heat sources. Stirling heat engine has long been proposed as a simple, reliable and efficient prime mover that converts heat to mechanical power for power generation. Despite huge research and development efforts on kinematic Stirling machine, it has proved difficult to compete against internal combustion counterpart due to problems of working fluid seals, lubrication and leakage [1]. Recently there has been interest in developing the Free Piston Stirling Engine (FPSE) configuration to address the design and reliability limitations of the kinematic type. Numerous advances in FPSE design have been demonstrated since its invention by Beale in the early 1960s. Similarly, a mathematical formulation of the Stirling cycle was only published 50 years later after its invention by the Robert Stirling in 1816. This analysis was made by Gustave Schmidt in 1871 [2]. The attractiveness of this analysis is that it produces closed-form solutions for the performance of the Stirling cycle [3]. Today, the design and performance analysis of a Stirling engine is carried out using the empirical and analytical models. The empirical models are mostly based on a dimensionless parameter called Beale number to predict the engine power depending on the engine other operating parameters such as frequency, pressure and swept volume and the analytical models are based on dynamic and thermodynamic analysis. Generally, the thermodynamic analysis of a Stirling engine

Manuscript received May 4, 2014; revised June 22, 2014.

S. Ghozzi and R. Boukhanouf are with The University of Nottingham, Department of Built Environment, Nottingham, UK (e-mail: salem.ghozzi@nottingham.ac.uk,rabah.boukhanouf@nottingham.ac.uk). cycle is very complex. This work presents the second-order analysis [4] which is more complex than Schmidt analysis as it eliminates the assumption of isothermal working spaces and ideal heat exchangers. The analysis also takes into account heat and pumping losses and regenerator inefficiencies. The computer codes have been developed and adopted for a novel Free Piston Stirling engine configuration to determine its design main parameters and predict the thermal performance in terms of its output power and thermal efficiency.

\section{DESCRIPTION OF THE FPSE TOPOLOGY}

The Free Piston Stirling Engine (FPSE) is made of two working space volumes, the expansion and compression space, which form part of the heat source and heat sink respectively. As shown in the proposed design of Fig. 1, these spaces are coupled through the heater, regenerator and cooler. The heater is a simple flat stainless steel plate. Sensible heat energy released in the combustion chamber is transferred though the heater wall to the working fluid in the engine. The cooler is made of an annular water jacket surrounding the compression space [5]. The regenerator is made of fine wire meshes and is packed in an annulus gap around the engine cylinder. The purpose of the regenerator is to store heat energy of the working fluid as it cycles between the expansion and compression space. If properly design, the regenerator will allow an increase of the efficiency of the Stirling cycle as it reduces large temperature swings in the expansion and compression space. The heat energy supply to the engine is does work on the working fluid which expansion and compression drives a power piston. A second piston (displacer) is located between the expansion space and the compression space circulates the working fluid between the expansion and compression space [6].

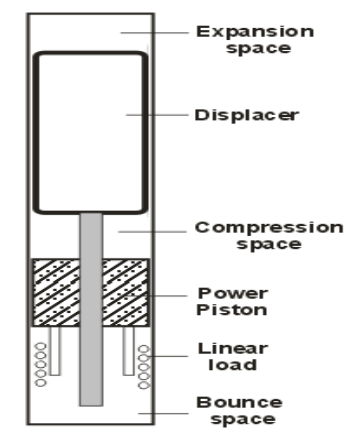

Fig. 1. General scheme for free piston stirling engine.

\section{A. The Proposed Design of FPSE}

Initially, a number of designs for the FP engine with bellows that can be practically manufactured have been proposed. However, the assembly and manufacture issues 
were taking into considerations in order to simplify the assembly and reduce the total cost. The displacer is made of light weight sealed metal cylinder. Since the displacer is located between the expansion space and the compression space, it experiences a large temperature gradient. The displacer is supported by a specially shaped metal bellows that act as mechanical springs. The bellows were designed to achieve a specific operating frequency and displacer stroke. Similarly, the power piston is mounted on another metal bellows to form a mass-spring oscillating component so that it is in position of free moving. The mechanical arrangement of the components of the engine is shown in Fig. 2. The sealed working fluid of the engine are cooled and heated through. For simplicity, the regenerator used in this engine is of the annular regenerator type that is housed around the displacer.

\section{B. Bellows Spring Design}

One of the main critical components of this design is the metal bellows that act as supporting mechanical springs for both the displacer and the power piston. The bellows were designed to have specific characteristics to meet the engine operating parameters. This includes, the bellows spring rate, maximum allowable stroke, operating temperature and number of operating cycles before failure. Fig. 3 shows a schematic diagram of the bellows used in the engine.

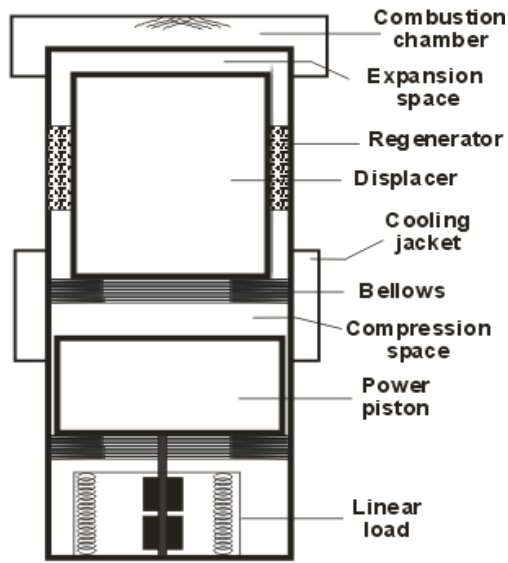

Fig. 2. The proposed design of the FPSE.

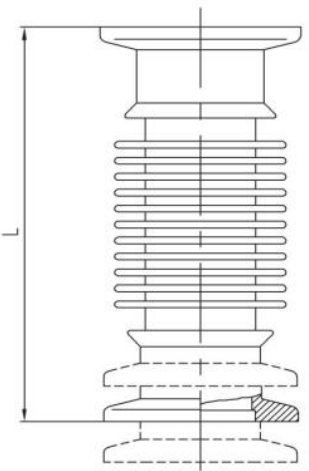

Fig. 3. General scheme for the bellows used in the engine.

\section{OUTLINE OF THERMAL MODELLING}

The thermal modelling of the engine was conducted using second order mathematical analysis based on finite cell method. This consists in subdividing the working fluid flow-passages, that is heat exchangers and connecting ports, into five homogenous control volumes; namely expansion space, heater, regenerator, cooler and compression space. Throughout this analysis it was assumed that perfect gas laws apply in each control volume and the flow is one-dimensional. Fig. 4 shows heat balance of a typical control volume cell. The expansion and compression control volumes were assumed to be sinusoids and adiabatic. The temperature of the heater and cooler were assumed to be constant and known and defined as initial conditions. The temperature gradient in the five control volumes of the engine is presented in Fig. 5.

The adiabatic model formulation was derived by applying the perfect gas laws, conservation of energy, mass, and momentum to each control volume as follows [7]:

$$
\begin{gathered}
d Q=d W-R T d m \\
P V=m R T \\
d m=m_{i}-m_{o}
\end{gathered}
$$

The differential form of the equation of state is given as following:

$$
\frac{d P}{P}+\frac{d V}{V}=\frac{d m}{m}+\frac{d T}{T}
$$

The values of heat transfer $(Q)$ for the heater and cooler cells are then used determine the actual operating temperature of the working fluid in the heater and cooler, as following:

$$
\begin{gathered}
T_{k}=T_{w k}-Q_{k} /\left(h_{k} A_{w g k}\right) \\
T_{h}=T_{w h}-Q_{h} /\left(h_{h} A_{w g h}\right)
\end{gathered}
$$

In this analysis, irreversibilites due to heat, pressure and friction losses in the heat are considered through using the number of transfer units (NTU) method. The heat exchangers effectiveness is then defined as follows [8]:

$$
\varepsilon=\frac{N T U}{(1+N T U)}
$$

where the $N T U$ is expressed as:

$$
N T U=N_{S T}\left(A_{w} / A\right) / 2
$$

And Stanton Number is given by:

$$
N_{S T}=h / \rho u c_{p}
$$

The working fluid "pumping losses" expressed as pressure drop across the heat exchangers is evaluated with reference to the compression space pressure as:

$$
\Delta P=\frac{f \rho L u^{2}}{2 d_{h}}
$$


Therefore, the effective engine work output could be given as follows:

$$
W=\oint P\left(d V_{e}+d V_{c}\right)-\oint \sum \Delta P d V_{e}=W_{i}+\Delta W
$$

where $\left(\mathrm{W}_{\mathrm{i}}\right)$ is the work done per cycle that is obtained from the ideal adiabatic analysis and $(\Delta \mathrm{W})$ is the pumping loss per cycle.

Equation (1), (2), (3) and (4) were set up for every control volume and then solved simultaneously using a second order Runge-Kutta method. It was assumed that the movement of the displacer and power piston are sinusoids and the operating frequency, working fluid mass, fluid type, and the geometry of the system were specified. The model was set up so that according to Urieli [2] it could be solved as an initial-value problem by assigning an appropriate initial conditions and integrating the differential equations until a steady state was reached.

The simulation computes all engine parameters over one complete thermodynamic cycle including the pressure and volume variation, cyclic energy input and output of the engine components, working fluid temperatures variation, and overall efficiency of the cycle.

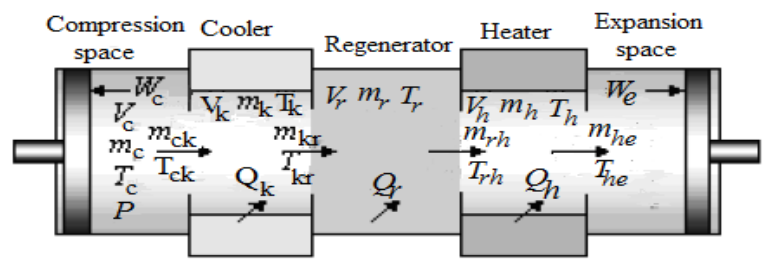

Fig. 4. The indicated variables for the Ideal Adiabatic approach [8].

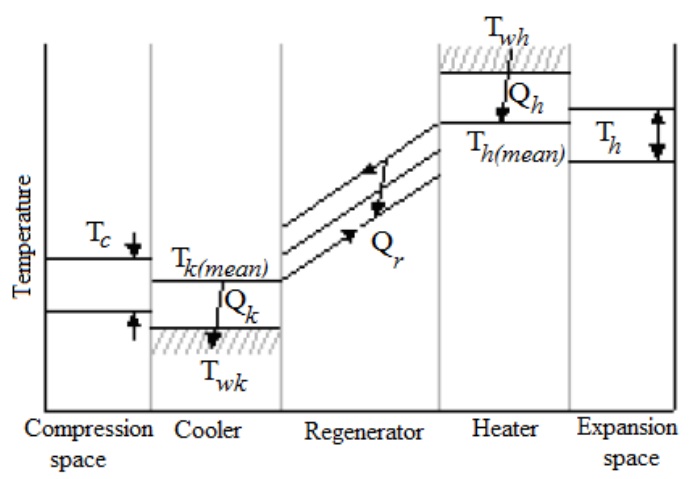

Fig. 5. Temperature variation of Simple analysis model [9].

\section{Simulation Results AND Discussion}

The design of the engine shown in Fig. 2 was analyzed and simulated in order to evaluate and validate the performance of the new engine design and calculate the output power with taking in consideration the pumping losses caused by the fluid friction as well as the imperfect of the heat exchangers. The operating parameters and the engine dimensions used in the simulation were defined by the user and identified to meet the criteria and the dimensions of a small scale proof-of-concept to be tested in the lab, which is under construction. The operating parameters and conditions are listed in Table I and the numerical results obtained from the simulation are presented in Table II. The temperature gradient in the cooler and heater and the ideal thermal performance of the engine (heat and frictional losses has yet not considered) are listed in the top of Table II. However, the actual engine performance (heat and frictional losses are considered) and the imperfect specifications of the regeneration.

Fig. 6 shows pressure variation in the expansion and compression space of the engine and the two pressure waveforms are nearly in phase, which underpins low pressure losses in the heat exchangers. On the other hand, the shift of the pressure variations of the Simple analysis from the Schmidt pressure variation is due to the perfect regeneration assumptions in the Schmidt analysis. Furthermore, it is observed that the maximum pressure is at $140^{\circ}$ for both analyses. Fig. 7 shows gas flow rate (GA) swept by the displacer and power piston between the engine cells in which a $90^{\circ}$ phase-shift was assumed and quasi-steady-flow is implied, thus the pressure at any moment is constant throughout the engine.

TABLE I: OPERATING PARAMETERS FOR THE SIMULATION

\begin{tabular}{lll}
\hline \hline Variable & Value & Unit \\
\hline Cold side wall temperature $\left(\mathrm{T}_{\mathrm{k}}\right)$ & 50 & ${ }^{\circ} \mathrm{C}$ \\
Hot side wall temperature $\left(\mathrm{T}_{\mathrm{h}}\right)$ & 300 & ${ }^{\circ} \mathrm{C}$ \\
Mean operating pressure $\left(\mathrm{P}_{\text {mean }}\right)$ & 2 & $\mathrm{bar}$ \\
Operating frequency $(\mathrm{f})$ & 20 & $\mathrm{~Hz}$ \\
\hline \hline
\end{tabular}

TABLE II: NUMERICAL RESULTS FROM SIMPLE ANALYSIS

\begin{tabular}{lll}
\hline \hline Variable name & Value & Unit \\
\hline User defined cold side wall temperature $\left(\mathrm{T}_{\mathrm{wk}}\right)$ & 50 & ${ }^{\circ} \mathrm{C}$ \\
Simulated cold side gas temperature $\left(\mathrm{T}_{\mathrm{k}}\right)$ & 60.4 & ${ }^{\circ} \mathrm{C}$ \\
User defined hot side wall temperature $\left(\mathrm{T}_{\mathrm{wh}}\right)$ & 300 & ${ }^{\circ} \mathrm{C}$ \\
Simulated hot side gas temperature $\left(\mathrm{T}_{\mathrm{h}}\right)$ & 277.6 & ${ }^{\circ} \mathrm{C}$ \\
Gas mass & 0.11 & $\mathrm{~g}$ \\
Pressure phase angle (beta) & 38.2 & degree \\
Schmidt thermal efficiency & 44 & $\%$ \\
Schmidt total outpour power & 0.85 & $\mathrm{~W}$ \\
Thermal efficiency of thermodynamic cycle & 39 & $\%$ \\
Total output power of thermodynamic cycle & 0.73 & $\mathrm{~W}$ \\
Heat power added by heater & 1.87 & $\mathrm{~W}$ \\
Heat power rejected by cooler & -1.15 & $\mathrm{~W}$ \\
Regenerator effectiveness & 10 & $\%$ \\
Regenerator net enthalpy loss & 107.9 & $\mathrm{~W}$ \\
Regenerator wall leakage & 11.7 & $\mathrm{~W}$ \\
Actual total output power & 0.73 & $\mathrm{~W}$ \\
Actual heat power required & 121.5 & $\mathrm{~W}$ \\
Actual efficiency & $\sim 1$ & $\%$ \\
\hline
\end{tabular}

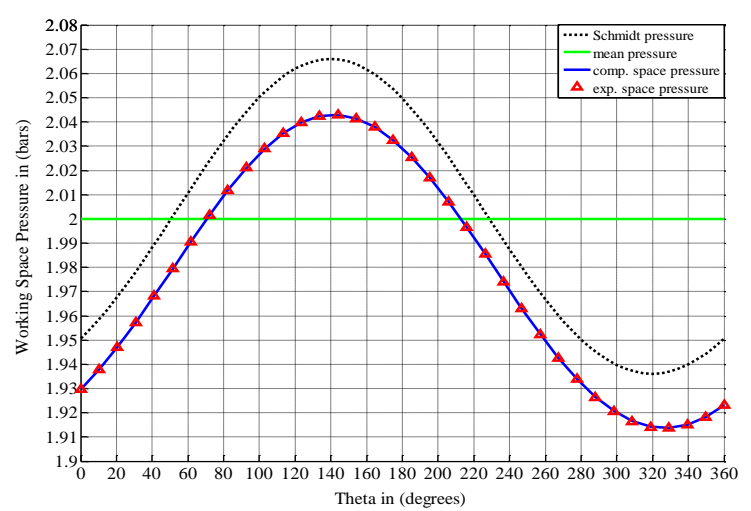

Fig. 6. Pressure variations in working spaces. 


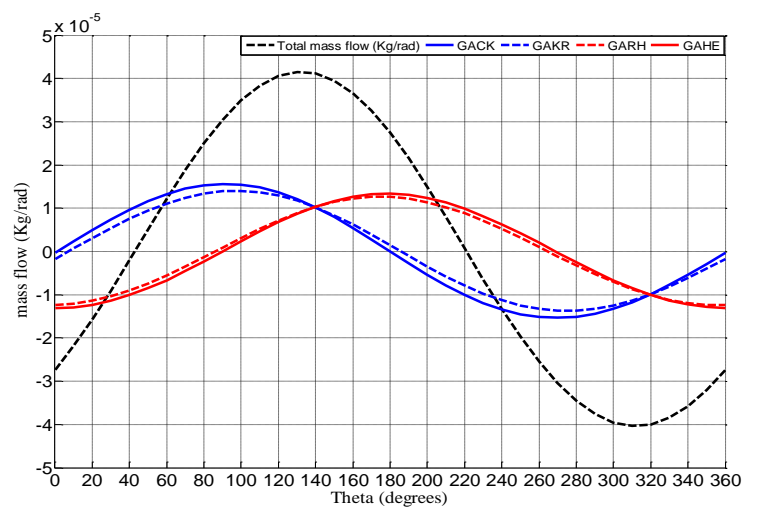

Fig. 7. Gas mass flow rate between the working spaces.

Fig. 8 shows a plot of the PV diagram which enclosed area is a measure of the power output of the engine. Although the PV diagrams are not in phase, it can be seen that the enclosed area of the both diagrams are almost similar. As consequence, the output powers of the both analyses are relatively similar. Referring to Table II, the output power of Schmidt stands at $(0.85 \mathrm{~W})$ and that of the simple analysis equals to $(0.73 \mathrm{~W})$. Heat transferred between the working spaces and the by the regenerator is presented in Fig. 9. It is observed that the heat rejected by the cooler $\left(\mathrm{Q}_{\mathrm{k}}\right)$ and the heat added by the heater $\left(\mathrm{Q}_{\mathrm{h}}\right)$, both were not that a huge values due to limited differential temperatures applied beside the small size of the engine.

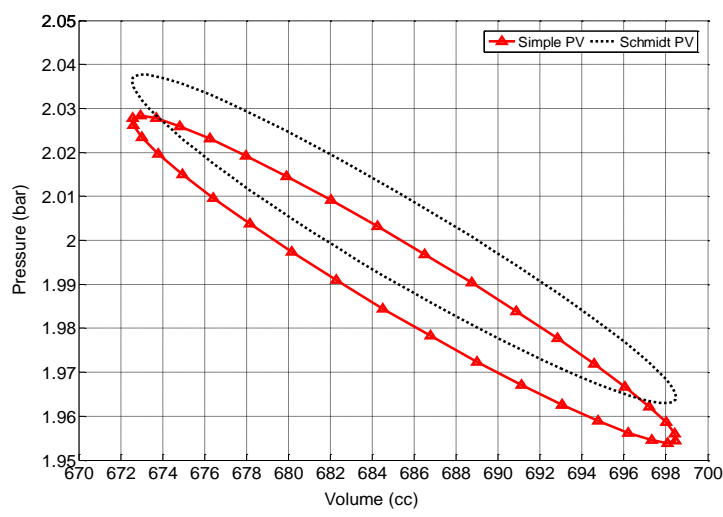

Fig. 8. PV diagram.

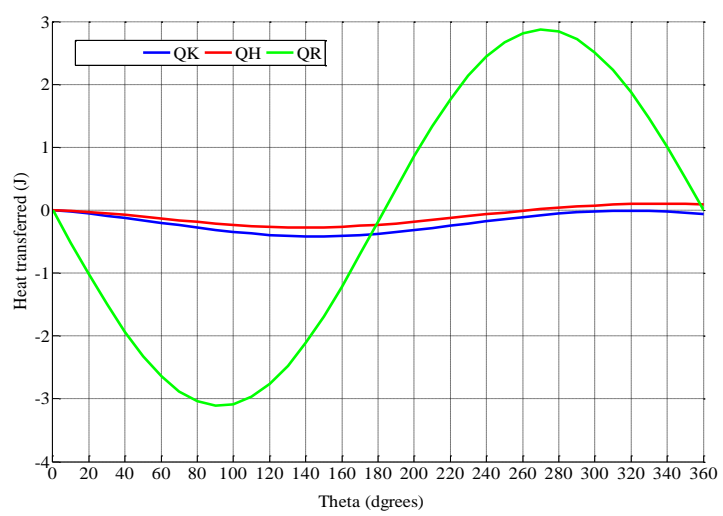

Fig. 9. Cyclic heat transferred within the engine cells.

Fig. 10 shows the temperature variations of the simple analysis model. It can be noticed that the mean effective temperature (gas temperature) for the real heater $\left(T_{h}\right)$ and cooler $\left(\mathrm{T}_{\mathrm{k}}\right)$ are respectively higher and lower than that of the heat exchanger wall temperatures $\left(\mathrm{T}_{\mathrm{wh}}\right)$ and $\left(\mathrm{T}_{\mathrm{wk}}\right)$. Therefore, the engine operates on temperature limits lower than that originally specified; consequently, the performance of the engine is negatively affected.

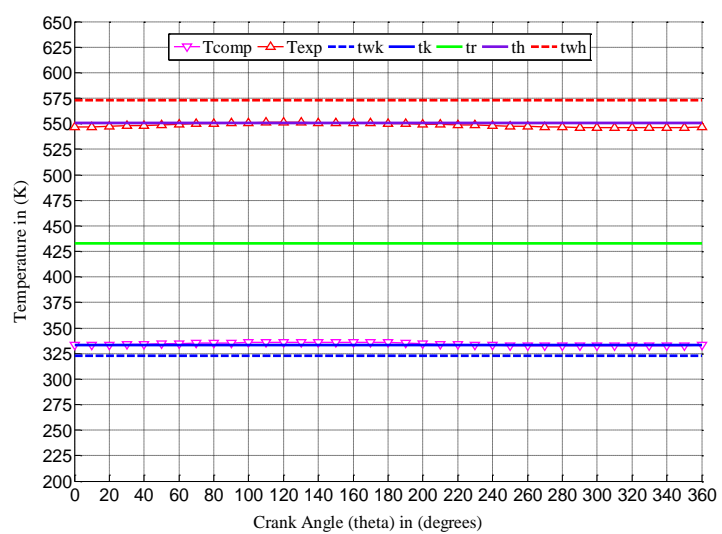

Fig. 10. Temperature gradient in the engine cells with the crank angle.

\section{CONCLUSION AND FURTHER WORK}

In conclusion, three simulation methods of varying complexity, which are the well-known Schmidt analysis, the Ideal Adiabatic analysis and the so-called Simple analysis, were implemented to analyze the thermodynamic cycle of a new design of Free-Piston Stirling engine and to calculate the output power and thermal efficiency of the engine as well as to evaluate the performance of the engine. The operating parameters and the size of the engine were determined to meet the criteria of a prototype of a small scale proof-of-concept is under construction to be tested in the lab to prove the results from the simulation. Referring to slightly low temperature limits $\left(50-300{ }^{\circ} \mathrm{C}\right)$ and low pressure ( 2 bar) identified by the user and the low effectiveness of the regenerator (10\%) used in the engine, its output power and thermal efficiency are satisfactory. Additional complex simulation method (Quasi Steady-State Flow method) is in progress to evaluate the methods used in this work and to extract further results in more details. On the other hand, a small scale proof-of-concept engine prototype will be tested in the lab to demonstrate the new design concept.

\section{APPENDIX}

Nomenclature:

$P$ : Pressure $(\mathrm{Pa})$

$P_{\text {mean }}:$ Mean pressure $(\mathrm{Pa})$

$V$ : Volume (m3)

$T$ : Temperature (K)

$W$ : Power output $(\mathrm{W})$

$Q$ : Heat energy (J)

$m$ : Mass (kg)

$f_{r}$ : Engine operating frequency

$f$ : Friction factor (-)

$L$ : Length (m)

$d$ : Diameter (m)

$u$ : Velocity $(\mathrm{m} / \mathrm{s})$

$\rho$ : Density $(\mathrm{kg})$

$\omega:$ Angular frequency $(\mathrm{rad} / \mathrm{s})$

GA: Mass flow rate $(\mathrm{Kg} / \mathrm{rad})$

$N T U$ : Number of Thermal Units (-) 


\author{
$R e$ : Reynolds Number (-) \\ $N_{S T}$ : Stanton Number (-) \\ $\varepsilon_{\text {reg }}$ : Regenerator effectiveness $(\%)$ \\ $h$ : Heat transfer coefficient $\left(\mathrm{W} / \mathrm{m}^{2} \mathrm{~K}\right)$ \\ $C_{p}$ : Specific heat capacity at constant pressure $(\mathrm{J} / \mathrm{kg} \mathrm{K})$ \\ $C_{v}$ : Specific heat capacity at constant volume $(\mathrm{J} / \mathrm{kg} \mathrm{K})$
}

\section{ACKNOWLEDGMENT}

The authors would like to acknowledge the financial support from the Libyan government in the form of $\mathrm{PhD}$ scholarship.

\section{REFERENCES}

[1] N. W. Lane and W. T. Beale, "Free-Piston Stirling Design Features," in Proc. 8th International Stirling Engine Conference, University of Ancona, Italy, 1997.

[2] I. Tlili and S. A. Musmar, "Thermodynamic evaluation of a second order simulation for Yoke Ross Stirling engine," Energy Conversion and Management, vol. 68, pp. 149-160, 2013.

[3] I. Urieli and D. M. Berchowitz, Stirling Cycle Engine Analysis, Bristol, Great Britain: Adam Hilger Ltd, 1984.

[4] F. Formosa and L. G. Fréchette, "Scaling laws for free piston Stirling engine design: Benefits and challenges of miniaturization," Energy, vol. 57, pp. 796-808, 2013.

[5] H. Karabulut, "Dynamic analysis of a free piston Stirling engine working with closed and open thermodynamic cycles," Renewable Energy, vol. 36, no. 6, pp. 1704-1709, 2011.

[6] R. Boukhanouf, "Diaphragm Stirling Engien," 2nd Heat Power Cycles (HPC), Paris, 2003.

[7] Stirling Cycle Machine Analysis. Stirling cycle mechanical analysis. (2012). [Online]. Available: http://www.ohio.edu/mechanical/stirling/engines/engines.html.
[8] H. Snyman, T. Harms, and J. Strauss, "Design analysis methods for Stirling engines," Journal of Energy in Southern Africa, vol. 19, no. 3, pp. 4-19, 2008.

[9] J. M. Strauss and R. T. Dobson, "Evaluation of a second order simulation for Sterling engine design and optimisation," Journal of Energy in Southern Africa, vol. 21, no. 2, pp. 17, 2010

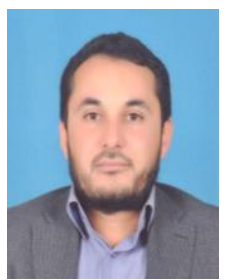

Salem Ghozzi has obtained his BEng degree in mechanical engineering, refrigeration \& air conditioning, from Faculty of Industrial Technology, Misurata, Libya in 2001. He also graduated with MSc degree in new \& renewable energy from the University of Durham, UK in 2010. Currently, he is a $\mathrm{PhD}$ researcher working on design and development of Stirling engine technology at the University of Nottingham, UK. Mr. Ghozzi had worked as a teache assistant in the University of Misurata, 2004-2007 and as Field Engineer for Al-Madar Al-Jadid for Mobile Networks, 2005-2008 and as Power \& Air Con. Manager, 2011-2012.

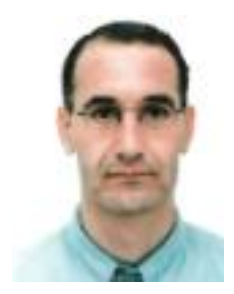

R. Boukhanouf is a lecturer in sustainable energy technologies at the Department of Built Environment, University of Nottingham. His experience in research and teaching in the area of energy efficient and low carbon technologies extends for over 15 years. He obtained his $\mathrm{PhD}$ degree in 1996 from the University of Manchester, UK.

Dr. Boukhanouf worked on numerous research projects funded by industry and government agencies in the area of small scale combined heat and power, active and passive heating and cooling systems for buildings, and advanced heat transfer enabling devices. He published a number of journal and conference papers and is named as the inventor in six international patents. 